\title{
Neuroinvasive and Neurotropic Human Respiratory Coronaviruses: Potential Neurovirulent Agents in Humans
}

\author{
Marc Desforges, Alain Le Coupanec, Élodie Brison, \\ Mathieu Meessen-Pinard and Pierre J. Talbot
}

\begin{abstract}
In humans, viral infections of the respiratory tract are a leading cause of morbidity and mortality worldwide. Several recognized respiratory viral agents have a neuroinvasive capacity since they can spread from the respiratory tract to the central nervous system (CNS). Once there, infection of CNS cells (neurotropism) could lead to human health problems, such as encephalitis and long-term neurological diseases. Among the various respiratory viruses, coronaviruses are important pathogens of humans and animals. Human Coronaviruses (HCoV) usually infect the upper respiratory tract, where they are mainly associated with common colds. However, in more vulnerable populations, such as newborns, infants, the elderly, and immune-compromised individuals, they can also affect the lower respiratory tract, leading to pneumonia, exacerbations of asthma, respiratory distress syndrome, or even severe acute respiratory syndrome (SARS). The respiratory involvement of $\mathrm{HCoV}$ has been clearly established since the 1960s. In addition, for almost three decades now, the scientific literature has also demonstrated that $\mathrm{HCoV}$ are neuroinvasive and neurotropic and could induce an overactivation of the immune system, in part by participating in the activation of autoreactive immune cells that could be associated with autoimmunity in susceptible individuals. Furthermore, it was shown that in the murine CNS, neurons are the main target of infection, which causes these essential cells to undergo degeneration and eventually die by some form of programmed cell death after virus infection. Moreover, it appears that the viral surface glycoprotein (S) represents an important factor in the neurodegenerative process. Given all these properties, it has been suggested that these recognized human respiratory
\end{abstract}

M. Desforges $(\bowtie) \cdot$ A. Le Coupanec · É. Brison · M. Meessen-Pinard · P. J. Talbot Laboratory of Neuroimmunovirology, INRS-Institut Armand-Frappier, Institut national de la recherche scientifique, Université du Québec, 531 boulevard des Prairies, Laval,

QC H7V IB7, Canada

e-mail: marc.desforges@iaf.inrs.ca

P. J. Talbot

e-mail: pierre.talbot@iaf.inrs.ca 
pathogens could be associated with the triggering or the exacerbation of neurological diseases for which the etiology remains unknown or poorly understood.

Keywords Respiratory viral infection - Coronavirus • Neuroinvasion - CNS infection - Neurological diseases

\section{Introduction}

Viral infections of the respiratory tract represent a major problem for human and animal health around the world. These respiratory infections induce the most common illnesses [1] and are a leading cause of morbidity and mortality in humans worldwide, especially children, the elderly, and immune-compromised individuals [2-4]. On a statistical basis, children represent a highly susceptible group, as they may experience multiple infections each year until they reach the age of 10 [5]. Respiratory viral infections also represent an economic threat for agriculture, especially in cattle, swine, and poultry production. The idea that viruses can cause respiratory tract infections has been demonstrated since the early 1930s [2]. Nevertheless, with the help of modern diagnostic tools, a significant number of new respiratory viruses have been discovered since the beginning of the twenty-first century and it is estimated that there are about 200 antigenically distinct viruses able to cause infection of the respiratory tract, especially in infants and children [6]. In fact, it is now believed that viruses cause $95 \%$ of respiratory diseases in children and infants, and about 30-40\% in the elderly [2].

Although the airway epithelial cells in the respiratory tract represent a first line of defense against pathogens, they can be targeted by several different respiratory viruses that can infect them as a way to penetrate the human host. Several infections are self-limited and the infection remains local as the virus is cleared by the immune system in the respiratory tract with minimal clinical consequences. However, in some circumstances, viruses can avoid the immune response and cause more severe respiratory diseases [1] or even spread to other tissues, including the central nervous system (CNS), where they could induce other types of pathologies [7].

\section{Neuroinvasive and Neurotropic Viruses: Associated Neuropathologies}

Over the years, the CNS has been shown to represent a frequent site of viral infection. Using different routes of entry, several different viruses, including respiratory pathogens, have been shown to be able to penetrate the CNS (neuroinvasion), where they can infect neurons and glial cells (neurotropism) and possibly 
induce or participate in the induction of neurological diseases (neurovirulence) [8]. In humans, a long list of viruses possess these "neuroproperties" and infection often leads to acute encephalitis, which can be fatal depending on virus tropism [9]. Rabies virus [10], herpes simplex virus (HSV) [11], and arthropod-borne flaviviruses [12] can induce encephalitis in humans. Chronic human neurological diseases may also be linked to viral infection. In acquired immunodeficiency syndrome (AIDS) dementia and related disorders, human immunodeficiency virus (HIV) induces neurodegeneration [13], which can result in motor dysfunctions and possibly cognitive impairments [14]. Progressive multifocal leukoencephalopathy (PML) is a human demyelinating disease [15] where prolonged immunosuppression leads to reactivation of latent polyoma JC virus (JCV) [16]. Subacute sclerosing panencephalitis (SSPE), a progressive fatal neurological disease, is caused by CNS persistence of measles virus [17]. Human T-cell lymphotrophic virus (HTLV-1) causes progressive tropical spastic paraperesis/HTLV-1-associated myelopathy (PTSP/ HAM) in 1-2 \% of infected individuals [18] and HSV-1 and human herpes virus 6 (HHV-6) were proposed to cause or exacerbate Alzheimer's disease (AD) [19].

As mentioned above, respiratory viral agents also have the capacity to invade the CNS where they will infect resident cells and potentially be neurovirulent in inducing a neuropathology. Several of these recognized respiratory pathogens can gain access to the CNS, where they can eventually cause health problems in humans.

\section{Respiratory Viruses with Neuroinvasive and Neurotropic Properties: Associated Neuropathologies}

Respiratory syncytial virus (RSV), the most common pathogen to cause lower respiratory tract infection in infants worldwide [20], is one such neuroinvasive respiratory agent that has been detected in the cerebrospinal fluid (CSF) of patients $[21,22]$ and that was associated with convulsions [23], febrile seizures, and encephalitis [24]. Furthermore, it was recently shown that RSV can spread from the airways to the CNS in mice after intranasal inoculation, and that it induces behavioral and cognitive impairments [25].

Measles virus (MV) from the Paramyxoviridae family is another common virus that causes a disease of the respiratory airways associated with fever, cough, and congestion. However, MV infection also induces other symptoms including a characteristic rash and Koplik's spots [26] in the oral mucosa. One of two most important sequelae associated with MV infection is immunosuppression, which facilitates infection by opportunistic bacteria or parasites that can lead to pneumonia or diarrhea. A second type of rare but significant sequelae is long-term CNS disease [26]. Postinfectious encephalomyelitis (PIE) or acute disseminated encephalomyelitis (ADEM) occurs in 1 of 1,000 measles cases in children and adolescents. Measles inclusion body encephalitis (MIBE) is a second CNS 
complication that can arise after a MV infection in immune-compromised patients. Finally, subacute sclerosing panencephalitis (SSPE) is a third form of CNS disease associated with MV infection. It is a slow progressive neurological disease that appears 6-10 years after infection in about 4-11 cases per 100,000 cases of measles (for review see [27]).

Hendra virus $(\mathrm{HeV})$ and Nipah virus $(\mathrm{NiV})$ are two members of the genus Henipavirus (HNV), also from the Paramyxoviridae family. They represent important emerging viruses that were discovered in the 1990s [28]. Fruit bats are the natural reservoir and both viruses can be transmitted to humans from intermediate reservoirs such as pigs and horses [29]. The HNV causes acute and severe respiratory disease in humans, including necrotizing alveolitis with hemorrhage, pulmonary edema, and pneumonia [28]. Neurological signs of pathology include confusion, motor deficits, seizures, febrile encephalitic syndrome, and reduced level of consciousness. Moreover, neuropsychiatric sequelae have been reported but it is not known whether postinfectious encephalomyelitis occurs following infection [29]. The use of animal models showed that the main route of entry into the CNS is the olfactory nerve [30].

Influenza virus comes in three types: A, B, and C. Types A and B cause the flu syndrome, characterized by chills, fever, headache, sore throat, and muscle pains [31], and are responsible for seasonal epidemics that affect 3-5 million humans, of which 250,000-500,000 cases are lethal each year [32]. Although influenza type C virus is less frequent in humans, it is also distributed around the world where it mainly infects infants and young children; most of the time infection results in mild upper respiratory tract illnesses. However, complications associated with lower respiratory tract infection do occur in children under 2 years of age [33, 34]. Human influenza A virus is of particular interest because of its capacity to recombine and rearrange with its avian and porcine counterparts to generate new emerging viruses that are introduced into the human population and that may lead to pandemic outbreaks associated with significant morbidity and mortality, as it was observed at least four times during the twentieth century and already once in the twenty-first century $[32,35]$. Influenza virus type A is highly contagious and, even though most infections are localized to the upper respiratory tract, some more severe cases may result in pneumonia [36] and even complications involving the CNS [37]. Several studies have shown that influenza A can be associated with encephalitis, Reye's syndrome, febrile seizure, acute necrotizing encephalopathy, and possibly acute disseminated encephalomyelitis (ADEM) in humans [31, 3841]. Making use of murine models, it has also been shown that influenza A virus could reach the CNS through the olfactory nerve route and alter hippocampal morphology or expression of synaptic regulatory genes while impairing cognition and emotional behavior [42, 43]. Influenza A virus was also described as a factor which may increase the risk of Parkinson's disease (PD) [37].

Among the different respiratory viruses, coronaviruses are important pathogens of humans and animals, causing a range of symptoms, including in the CNS. 


\section{Coronaviruses}

Coronaviruses, a family of enveloped positive-stranded RNA viruses with a characteristic crown-shaped appearance, are widespread in nature and can infect several different species [44], in which they cause mainly respiratory and enteric pathologies, with neurotropic and neuroinvasive properties in various hosts including humans, cats, pigs, rodents, and fowl [45-48].

They are taxonomically grouped in the family Coronaviridae, within the order Nidovirales, and they are classified within four different genera, namely Alpha, Beta Gamma, and Deltacoronaviruses [49, 50]. They form a group of enveloped viruses that have the largest genome among RNA viruses. This non-segmented $30 \mathrm{~kb}$ positive single-stranded polyadenylated RNA possesses 4 or 5 genes encoding structural proteins ( $\mathrm{S}, \mathrm{E}, \mathrm{M}, \mathrm{N}$; HE for the genus Betacoronaviruses) and several genes encoding non-structural proteins.

The spike protein $(\mathrm{S})$ is a type-1 glycosylated transmembrane protein responsible for the recognition of the cellular receptor used by the virus to infect a susceptible cell. The envelope (E) protein is a small structural protein anchored in the viral envelope, and which has a role in the assembly of the virion; it appears to be responsible for the adequate curving of the viral envelope. The membrane (M) protein possesses three transmembrane domains and interacts with all the other structural viral proteins and therefore helps to shape and maintain the virion structure. The nucleocapsid $(\mathrm{N})$ protein associates with the viral genome and plays an essential role in encapsidating it into a helical nucleocapsid within the viral particle. The hemagglutinin-esterase (HE) is only present in most species of the betacoronavirus genus. Like the $\mathrm{S}$ protein, it is a transmembrane protein which forms homodimers and which interacts with different types of sialic acid, associated with an apparent role in hemagglutination. It also possesses an acetylesterase function, which may be important early during infection or during the release of viral particles from the infected cells at the end of the replication cycle of the betacoronaviruses [48].

\section{Animal Coronaviruses: Pathogens of the Respiratory Tract and the Central Nervous System}

As mentioned above, coronaviruses are widespread in nature and can infect several different animal species, in which very often they are both respiratory and enteric pathogens. Although several animal coronaviruses induce severe enteric diseases, they also often reach the respiratory tract, where they can be associated with mild to severe diseases. Some examples of coronaviruses that can infect livestock or poultry, in which they have a respiratory tropism, are transmissible gastrointestinal virus (TGEV) and its associated $\mathrm{S}$ protein deletion mutant: porcine respiratory coronavirus (PRCoV) and porcine hemagglutinating encephalitis virus (PHEV), 
which infect swine; bovine coronavirus $(\mathrm{BCoV})$, which infects cattle; and infectious bronchitis virus (IBV), which infects chicken [51]. Several of these animal coronaviruses cause severe economic burden to poultry, swine, and cattle industries worldwide. Other animal coronaviruses that have a respiratory tropism are feline coronavirus $(\mathrm{FCoV})$; canine respiratory coronavirus $(\mathrm{CRCoV})$; and bat $\mathrm{CoV}$, which infects the bat species Miniopterus [51].

Among the respiratory animal coronaviruses, FCoV and PHEV have been associated with neurological diseases. Neurological symptoms may occur in cats infected with a highly virulent FCoV variant, designated FIPV [52, 53]. Neurological disease appears partially immune-mediated and may result in uncontrolled secretion of cytokines [54] that leads to diverse pathological manifestations including meningitis [55] and even spinal cord involvement [56]. Furthermore, there is often a small amount of infectious FCoV present in brain tissue [52]. The PHEV was isolated from the brains of suckling pigs suffering from encephalomyelitis several years ago in Canada [57] and the disease could be reproduced experimentally in piglets following intranasal inoculation [58]. After oronasal infection, it was shown that the virus first infects epithelial cells of the respiratory tract and small intestine and, using retrograde neuronal spreading via peripheral nerves, was able to enter the CNS [59]. More recently, the neuroinvasiveness and neurotropism of the virus were again demonstrated in a murine model, where PHEV induced a poor inflammatory reaction in the CNS and infected cells showed no cytopathological changes [60].

The last, but not the least, example of another animal coronavirus, i.e., neuroinvasive, neurotropic, and neurovirulent, is mouse hepatitis virus (MHV). This virus is a subspecies of the species murine coronavirus (MuCoV) [49], which represents a collection of viral strains with different tropism, including respiratory for the MHV-1 strain, and neurotropic for the MHV-JHM and MHV-A59 strains. In susceptible mice, these two latter strains of MHV induce a demyelinating disease that resemble human multiple sclerosis (MS) [61].

Coronaviruses are all molecularly related in structure and mode of replication [62]. Therefore, the close structural and biological relatedness of $\mathrm{HCoV}$ to the neurotropic animal coronaviruses has led to speculation about possible involvement of $\mathrm{HCoV}$ in neurological diseases. Till now, no clear specific association has ever been made between coronaviruses and any known human neuropathology. However, HCoV-229E and HCoV-OC43 [63-66], as well as SARS-CoV [67, 68], were shown to be neuroinvasive and neurotropic.

\section{Human Coronaviruses: Respiratory Pathogens}

Human coronaviruses $(\mathrm{HCoV})$ usually infect the upper respiratory tract, where they are mainly associated with common colds. However, in more vulnerable populations such as newborns, infants, the elderly, and immune-compromised individuals, they can also reach the lower respiratory tract, where they could 
instead be associated with pneumonia, exacerbations of asthma, respiratory distress syndrome or even severe acute respiratory syndrome (SARS) [44, 69].

Ever since their discovery in the late 1960s, coronaviruses able to infect humans were neglected by the international medical community. However, when a variant emerged from animals in Southeast Asia to cause the first pandemic of the twentyfirst century: the severe acute respiratory syndrome or SARS, these apparently innocuous viruses suddenly became "more interesting." Indeed, the 2002-2003 SARS pandemic was caused by a coronavirus variant that appears to have emerged from a bat reservoir to infect palm civets, sold live in open markets, which served as intermediate reservoirs before crossing into humans. Moreover in the fall of 2012, 10 years after the SARS episode, the World Health Organization (WHO) warned the international medical community, that a SARS-like disease affected individuals that traveled from the Arabian Peninsula to the United Kingdom, which may indicate a possible resurgence of SARS. However, using molecular sequencing, it was rapidly shown that this new respiratory coronavirus was genetically different from SARS-CoV, underlining the importance of a molecular approach in making a viral diagnostic. It is now recognized that the new epidemic is caused by a new coronavirus from the genus Betacoronavirus that was first named HCoV-EMC (for Human Coronavirus-Erasmus Medical Center), human betacoronavirus $2 \mathrm{c}$, and $\mathrm{NCoV}$ or $\mathrm{nCoV}$ (for novel Coronavirus), and that is now known under the official name MERS-CoV: the Middle-East Respiratory Syndrome Coronavirus [50]. As of August 30, 2013, WHO indicated that the MERS$\mathrm{CoV}$ has spread to eight different countries, where 108 laboratory-confirmed cases of individuals have been identified as infected by the MERS-CoV, with 50 deaths [70].

Although coronaviruses that infect humans are mainly recognized respiratory pathogens, as they usually first target respiratory and mucosal surfaces, infectious particles, antigens or RNA, were detected in other tissues than the respiratory tract, including the CNS.

\section{Human Coronaviruses in the CNS}

The detection of HCoV RNA in human brain samples clearly demonstrates that these respiratory pathogens are naturally neuroinvasive in humans and suggests that they establish a persistent infection in human CNS [63]. Furthermore, we have shown that these viruses are able to establish a persistent infection in human cells representative of the CNS $[64,65]$ and that HCoV-OC43 RNA could be detected for at least a year in the CNS of infected mice that survived the virus-induced acute encephalitis [71]. Therefore, an apparently innocuous human respiratory pathogen may persist in the human CNS as a component of what is proposed to be a «viral flora» of the brain, like HSV in a large proportion of the population. It would therefore be possible that such a persistent infection may become a factor or cofactor of neuropathogenesis in genetically or otherwise predisposed individuals. 
Human coronaviruses were first isolated in the mid-1960s from patients with upper respiratory tract disease [72]. Until the end of the twentieth century, only two serological groups, represented by strains OC43 and 229E, were known to infect humans and they were recognized as respiratory pathogens responsible for up to $30 \%$ of common colds [72]. Over the last 10 years, SARS has generated renewed interest in coronaviruses that led to the discovery of new coronaviruses that can infect humans: SARS-CoV [73, 74], HCoV-NL63 [75], HCoV-HKU1 [76] and MERS-CoV [77]. Among these six coronaviruses, at least HCoV-229E and $\mathrm{HCoV}-\mathrm{OC} 43$, as well as SARS-CoV, possess neuroinvasive properties as viral RNA [63] or infectious virus [67, 68] can be detected in human brains.

To our knowledge, there exist no reports on the detection of HCoV-HKU1, HCoV-NL63, and MERS-CoV in the human CNS. On the other hand, neurological symptoms have been described in association with both HCoV-HKU1 and HCoVNL63 [78] and a recent report, which evaluated MERS-CoV cell tropism, suggest that, among several cell lines representative of different tissues and organs, this virus seems to be able to infect the neuron-committed human cell line NT2 [79].

\section{Possible Mechanisms of Neuroinvasiveness}

Viruses may enter the CNS through two distinct routes: hematogenous dissemination or neuronal retrograde dissemination. Hematogenous spread involves the presence of a given virus in the bloodstream and retrograde viral spread toward the CNS occurs when a given virus infects neurons in the periphery and uses the transport machinery within those cells to gain access to the CNS [80].

In order to be neuroinvasive, viruses such as $\mathrm{HCoV}-229 \mathrm{E}, \mathrm{HCoV}-\mathrm{OC} 43$, and SARS-CoV may use both entry routes from the periphery. The hematogenous route involves the presence of a given virus in the blood, where it can either remain free for a period of time before it can infect the endothelial cells of the blood-brain-barrier (BBB), or infect leukocytes that will become some sort of viral reservoir for dissemination to other sites. Both situations occur during HIV infection of the CNS. Indeed, HIV-infected leukocytes that migrate through the BBB (called the Trojan horse [81]), is one of the route of spread, and direct infection of endothelial cells of the BBB is also possible even though the viral replication is at a low level [82].

Infection of human monocytes/macrophages by HCoV-229E and HCoV-OC43 was reported $[83,84]$ and infection by $\mathrm{HCoV}-229 \mathrm{E}$ of murine dentritic cells expressing the human aminopeptidase $\mathrm{N}$ [85] suggests that human coronaviruses may use these cells to disseminate to other tissues, including the CNS, where they could be associated with other type of pathologies. SARS-CoV was also shown to be able to infect human monocytes/macrophages $[68,86]$. Moreover, monocytederived dendritic cells are also susceptible to infection by SARS-CoV [87].

Human primary monocytes are activated following infection by HCoV-229E [83]. Since they eventually become macrophages as they invade tissues, this activation suggests that $\mathrm{HCoV}-229 \mathrm{E}$-infected monocytes would serve to facilitate 
their passage toward other tissues including the CNS, especially in immunecompromised individuals, as this was observed for murine cytomegalovirus (MCMV) [88]. The fact that HCoV-229E could only infect partially immunecompromised transgenic mice [89] suggests that HCoV-229E could take advantage of an immune-suppressed environment and disseminate to the CNS within susceptible individuals. The establishment of a persistent infection in a human leukocytic cell line [83] is also consistent with the possibility that monocytes/ macrophages serve as a reservoir and vector for this neuroinvasive $\mathrm{HCoV}$ [63]. The SARS-CoV also infects monocytes/macrophages $[68,86]$ and dendritic cells, in which it modulates innate immunity [87]. These cells could also serve as a reservoir for the virus to reach and maintain itself in the CNS. Our results indicate that $\mathrm{HCoV}$ could also infect human endothelial cells of the BBB in culture (unpublished data) and it has been speculated that SARS-CoV could do the same after viremia [90]. Therefore, the neuroinvasive HCoV could use the hematogenous route to penetrate into the CNS.

The second form of any viral spread toward CNS is through neuronal dissemination, where a given virus infects neurons in periphery and uses the machinery of active transport within those cells in order to gain access to the CNS [80]. After an intranasal infection, both HCoV-OC43 [91] and SARS-CoV [92] were shown to infect the lungs in mice and to be neuroinvasive as HCoV-OC43 [93, 94] and SARS-CoV [95] were detected in the CNS of susceptible mice. Therefore, these two coronaviruses may use both the hematogenous and transneuronal route toward the CNS.

Furthermore, as shown in Fig. 1, once in the brain, HCoV-OC43 can disseminate from the olfactory bulb to the cortex and we have previously shown that it could also reach the medulla, while the cerebellum remained almost uninfected. The hippocampus represents another specific structure infected by HCoV-OC43 in the brain (Fig. 1) and once in this region of the brain, the virus appears to spread by a transneuronal route before it eventually reaches the spinal cord [48].

\section{Mechanisms of HCoV-Induced Neurodegeneration and Programmed Cell Death: Possible Associated Neuropathologies}

Neuroinvasive viruses can damage the CNS as a result of misdirected host immune responses (virus-induced neuroimmunopathology) and/or viral replication, which directly induces damage to CNS cells (virus-induced neuropathology). In acute encephalitis, viral replication occurs in the brain tissue itself, possibly causing destructive lesions of the gray matter [47]. As mentioned above (Section "Neuroinvasive and Neurotropic Viruses: Associated Neuropathologies"), chronic human neurological diseases may also be linked to viral infection. However, in several cases of these chronic diseases, it is difficult to ascertain a role for any given virus, in part due to the difficulty of establishing the time at which these viruses become involved. Also, the four Koch's postulates for disease induction dictate whether a particular infectious agent causes a specific disease [96]. 


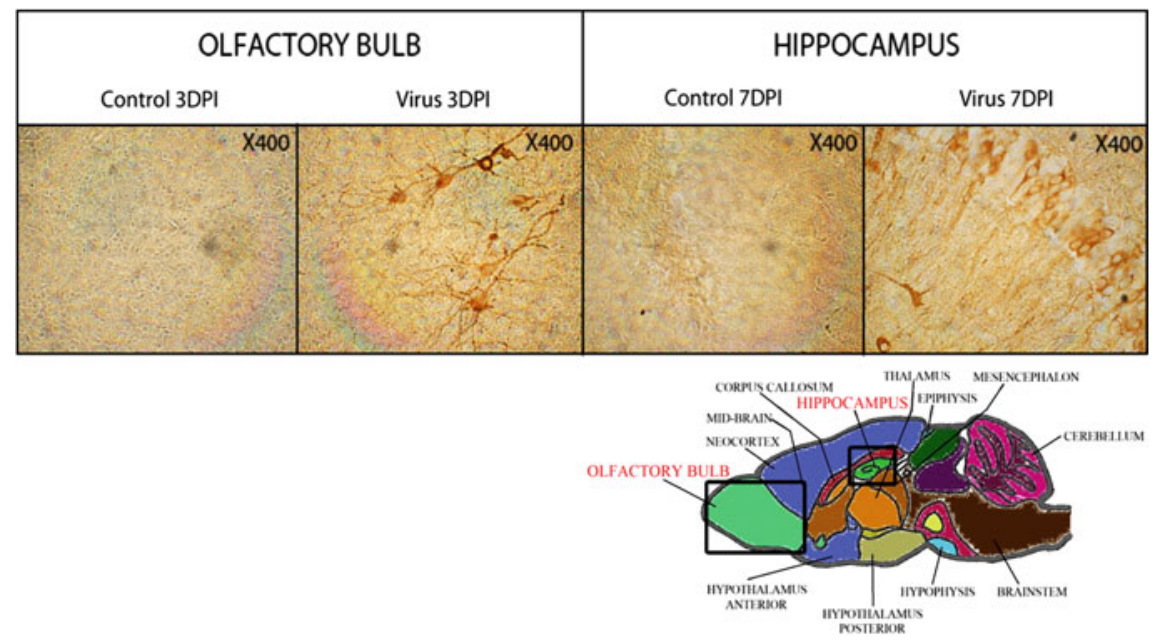

Fig. 1 Illustration of the transneuronal route used by HCoV-OC43 for neuroinvasion and dissemination into the central nervous system. The left panel shows the olfactory bulb area, either mock-infected (control) or HCoV-OC43-infected (virus) at 3 days postinfection (DPI). The right panel shows the hippocampus, either mock-infected (control) or $\mathrm{HCoV}-\mathrm{OC} 43$-infected (virus) at 7 days postinfection (DPI). In both regions of the brain, neurons are the target of infection. Magnification is $400 \mathrm{X}$

However, several viral infections, especially slow viral infections related to diseases that are rare manifestations of an infection, represent situations where Koch's postulate should be modified to better adapt to the situation [97, 98]. A series of new criteria, adapted from Sir Austin Bradford Hill's criteria for causation [98], has been elaborated by Giovannoni and collaborators [99] and should replace Koch's postulates when one wants to evaluate the relevance of any given virus in relation to MS etiology [99] or any other long-term human neurological diseases potentially related to a viral infection as well, including infection by human coronaviruses.

\section{Possible Coronaviral-Induced Neuroimmunopathology}

The presence of $\mathrm{HCoV}-229 \mathrm{E}$ and $\mathrm{HCoV}-\mathrm{OC} 43$ was detected in various neurological diseases in humans, including PD and MS [63] and ADEM [100].

Multiple sclerosis truly represents a human neurological disease where an infectious agent or agents may play a triggering role, with viruses the most likely culprit in genetically predisposed individuals [101]. There is a presumption that several neurotropic viruses could be involved in MS pathogenesis but that they may do so through similar direct and/or indirect mechanisms [102-105]. However, research has not yet led to a direct link to any specific virus or other microbes with MS. Association of coronaviruses with MS was suggested in numerous reports that 
Table 1 Detection of viral RNA in brain samples and of cross-reactive T-cell clones between myelin and $\mathrm{HCoV}$ antigens in control and MS patients

\begin{tabular}{lllll}
\hline & Gender & HCoV-OC43 & HCOV-229E & Both \\
\hline Normal controls & Male & $4(19)$ & $9(19)$ & $4(19)$ \\
& Female & $1(5)$ & $2(5)$ & $0(5)$ \\
AD, PD, ALS and OND & Male & $2(13)$ & $6(13)$ & $2(13)$ \\
& Female & $1(13)$ & $3(13)$ & $0(13)$ \\
Multiple Sclerosis & Male & $7(20)$ & $11(20)$ & $5(20)$ \\
& Female & $7(19)$ & $9(19)$ & $6(19)$ \\
\hline
\end{tabular}

\begin{tabular}{llllllll}
\hline T cell clones & \multicolumn{2}{l}{ Monospecific } & & \multicolumn{2}{l}{ Cross reactive } \\
\cline { 2 - 3 } & HCoV & Myelin & & 229E & OC43 & MBP & PLP \\
\hline Normal controls $\mathrm{n}=6$ & 28 & 7 & & 0 & 0 & 0 & 0 \\
Multiple Sclerosis $\mathrm{n}-32$ & 114 & 31 & & 4 & 2 & 2 & 2
\end{tabular}

Adapted from Arbour et al. [63] and Boucher et al. [108]

Numbers in the upper portion indicate the number of individuals positive for viral RNA and numbers in parenthesis indicate the total number of individuals tested

Numbers in the lower portion indicate the number of T-cell clones obtained. Monospecific describes clones that react against a single antigen and cross reactive describes clones that react both with $\mathrm{HCoV}$ and myelin antigens

are reviewed elsewhere [48]. One of these reports demonstrated a significant association of colds with MS exacerbations and a significant association of HCoV229E infection in MS patients [106] and another report on the association of viral infections and MS [107] commented that seasonal HCoV infection patterns do fit the observed occurrence of MS exacerbations. Furthermore, the case of these human coronaviruses in the CNS may represent a new example where the traditional Koch's postulates should be replaced by the previously cited adapted Hill's criteria [99].

More than a decade ago, we experimentally confirmed that HCoV-OC43 and $\mathrm{HCoV}-229 \mathrm{E}$ were naturally neuroinvasive in humans. Although viruses were also detected in some control brains, there was a significantly higher prevalence of $\mathrm{HCoV}-\mathrm{OC} 43$ in brains of MS patients [63]. Moreover, these data, in association with the observation that autoreactive T-cells recognized both viral and myelin antigens in MS patients but not in controls [108, 109] during infection by HCoVOC43 and HCoV-229E, suggest that the immune response may participate in the induction or exacerbation of neuropathologies such as MS in genetically or otherwise susceptible individuals (data summarized in Table 1). Furthermore, even though the use of the immunosuppressive drug cyclosporin $\mathrm{A}$ in $\mathrm{HCoV}$ OC43-infected mice resulted in a faster onset of encephalitis, suggesting a role for T-cells in viral clearance and survival with no related immunopathology [71], it was shown that in recombination activation gene (RAG) knock-out mice, HCoVOC43-induced encephalitis could be partially mediated by the T-cell response to infection [93]. The participation of different types of T-cells has been shown to play a significant role in the demyelinating neurological disease induced by the 

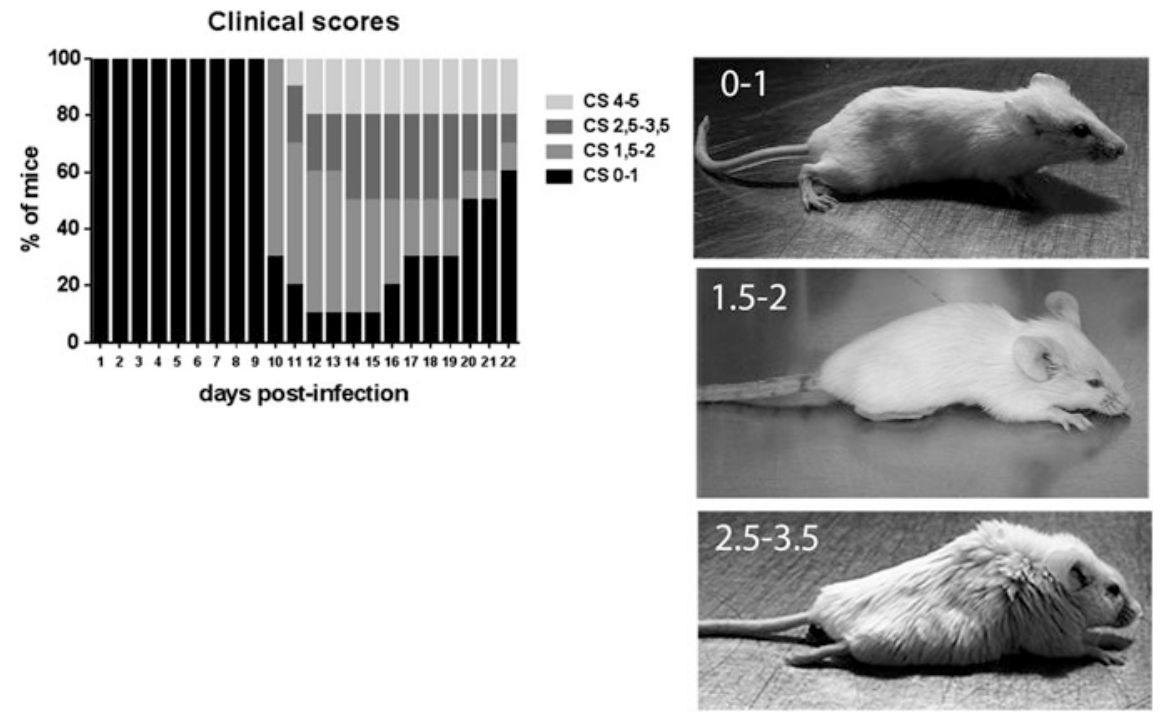

Fig. 2 Evaluation of the clinical scores (CS) related to motor dysfunctions (paralysis) of HCoVOC43 infected mice. The left panel shows the percentage of mice observed at each of the different degree of motor dysfunctions over the course of infection, from 0 to 21 days postinfection. The CS were established according to a scale based on the recognized experimental allergic encephalitis (EAE) model ( $0-1$ normal mouse with no clinical signs; $1.5-2$ partial hindlimb paralysis, with a walk close to ground level; $2.5-3.5$ complete hind-limb paralysis, and 4-5 moribund state or death. The right panels are a representation of mice at each stage of paralysis

murine $\mathrm{CoV}$, in particular for strain MHV-JHM [110], which represents the murine counterpart of $\mathrm{HCoV}-\mathrm{OC} 43$.

More recently, making use of another mouse model, we showed that HCoVOC43 induced immune cell infiltration and cytokine production in mouse CNS and that this response was significantly higher after infection by variants which harbor point mutations in the viral surface glycoprotein (S) [111]. Importantly, these $S$ point mutations were acquired after persistent infections of human neural cell lines [112]. Moreover, we also showed that infection by the $\mathrm{S}$ mutants is linked to glutamate excitotoxicity [113]. Therefore, as this increase in cytokine production may induce damages to the neurons [114] that can be associated with problems in glutamate homeostasis, which in the end may create glutamate excitotoxicity [115], it can contribute to neuronal degeneration associated with hind-limb paralysis, as illustrated in Fig. 2, and possible demyelination [111, 113]. The outcome of the observed degeneration of neurons may eventually lead to the death of these essential cells.

As previously mentioned, infection of neurons by itself may also participate in the process of cell death by directly generating a cytotoxic insult related to viral replication and/or to the induction of different cell death pathways. 


\section{Direct Viral-Induced Neuropathology}

When present in the murine CNS, HCoV-OC43 infects neurons in several different regions of the brain [48] (Fig. 1) before reaching the spinal cord. Infection of these essential cells induces their degeneration [111, 113], as observed by aberrant state of neurofilament phosphorylation, a situation that often leads to cell death and that could be directly induced by viral replication. Furthermore, using two model cell lines of differentiated human neurons, we demonstrated that programmed cell death (PCD) was induced after HCoV-OC43 infection [116, 117] and that the inhibition of viral replication was also in direct correlation with increased cell survival, suggesting that infection and production of new infectious viruses directly participate in the process of degeneration and eventual death of neurons. Our results indicate that the underlying mechanisms appear to involve different cellular factors and pathways, including caspase-independent apoptosis, parthanatos, and necroptosis, three forms of programmed cell death (PCD), which are reviewed elsewhere by the Nomenclature Committee on Cell Death (NCCD) [118]. These cell death pathways can act separately but may also interact in response to a stimulus (including a viral infection), as they share some of the cellular factors involved in the overall process that leads to cell death and that often converges toward mitochondria [118]. Figure 3 is a tentative representation of the various pathways and cellular factors involved during $\mathrm{HCoV}-\mathrm{OC} 43$-induced PCD of infected neurons. It is based on our data $[111,113,116,117]$ and on the scientific literature that describes some molecular pathways (parthanatos, necroptosis and apoptosis) and cellular factors, including calcium overload, endoplasmic reticulum (ER) stress, excitotoxicity, poly(ADP-ribose) polymerase (PARP), calpain and oxidative stress related to the formation of reactive oxygen species (ROS) involved in mitochondrial dysfunction, and eventual neurodegeneration and neuronal cell death [118-120]. Virus-cell interaction is always important in the regulation of cell response to infection. For $\mathrm{HCoV}-\mathrm{OC} 43$, we clearly showed that the viral $\mathrm{S}$ glycoprotein is an important factor of neurovirulence and neurodegeneration of infected cells $[111,113,116]$. This was similarly shown for coronavirus strains MHV-A59 and MHV-JHM, which represent subspecies of the MuCoV species, the murine counterpart of $\mathrm{HCoV}-\mathrm{OC} 43$ as they are both members of the Betacoronavirus genus. Indeed, several reports and reviews have, over the years, described that $S$ protein of this neuroinvasive and neurotropic murine coronavirus is a major factor associated with neurovirulence during encephalitis and the eventual demyelinating disease in susceptible mice $[121,122]$. Our more recent data also demonstrated that the $\mathrm{HE}$ protein is an important factor for the production of infectious $\mathrm{HCoV}-\mathrm{OC} 43$, suggesting an attenuation of the eventual spread of viruses deficient in fully active HE protein into the CNS [123]. Therefore, as the infection of neuronal cells apparently directly participate in the induction of neuronal death, by abrogating the production of infectious virus, the $\mathrm{HE}$ protein of $\mathrm{HCoV}-\mathrm{OC} 43$ could play a role in neurovirulence of $\mathrm{HCoV}-\mathrm{OC} 43$, like it does for MHV [124]. 


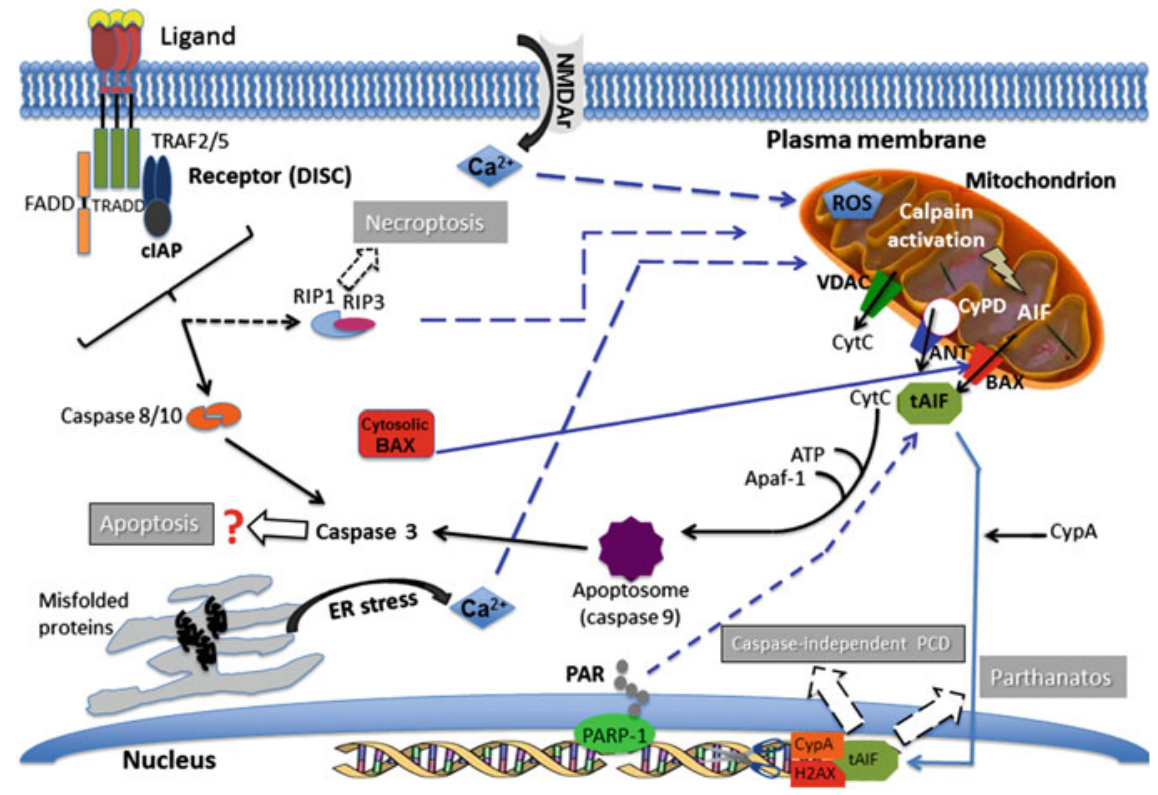

Fig. 3 Pathways of neuronal degeneration and cell death induced by HCoV-OC43 infection. Several cellular factors that regulate various mechanisms are activated in response to infection, which leads to programmed cell death (PCD). (1) Hallmarks of apoptosis, including relocalization of the activated pro-apoptotic protein $\mathrm{BAX}(\mathrm{Bcl}-2$ associated protein $\mathrm{X}$ ) from the cytosol to the mitochondrial membrane, cytochrome $\mathrm{C}$ release from mitochondria toward the cytosol, DNA fragmentation, and activation of caspases -3 and -9 , are observed during infection of human neurons. However, using a pan-caspase inhibitor (Z-VAD-fmk), cell death is not abrogated after infection, suggesting a caspase-independent type of apoptosis. (2) Relocalization of the mitochondrial protein AIF (apoptosis-inducing factor) toward the nucleus (tAIF) is observed after infection and participates in DNA fragmentation in conjunction with CypA (cyclophilin A) and histone H2AX. The AIF is known to be activated during caspase-independent apoptosis. However, AIF is also involved in Parthanatos, another form of PCD potentially associated with neurodegeneration. As they are synthesized by the poly(ADP-ribose) polymerase (PARP) during a neuronal stress, including during $\mathrm{HCoV-OC43}$ infection, polymers of ADPribose (PAR) may relocalize toward mitochondria and participate in the activation and relocalization of AIF toward the cytosol before it reaches the nucleus. Cyclophilin D (CypD) inhibition decreases AIF release from mitochondria and abrogates cell death induced by infection. (3) AIF release from mitochondria may be induced through its truncation (tAIF) by activated calpain, which is usually activated by a rise in the mitochondrial calcium concentration. (4) This increase in calcium concentration may be linked with either an important entry from the extracellular milieu (for instance during excitotoxicity) or with a release of calcium from the endoplasmic reticulum (ER) following induction of ER stress. Both situations are probably taking place after infection of neurons by $\mathrm{HCoV}-\mathrm{OC} 43$. The increase in calcium concentration in mitochondria may also induce production of reactive oxygen species (ROS) that can be harmful for mitochondria and hence neurons. (5) The presence during infection of an inhibitor (Nec-1) of the receptor interacting protein kinase-1 (RIP-1), significantly increases cell survival and partially abrogates viral replication, suggesting that necroptosis, a third form of PCD which involves RIP1 and RIP-3 downstream of the tumor necrosing factor (TNF) receptor family (in the form of the death-inducing signaling complex (DISC)), may play a role in HCoV-OC43-induced neuronal death. Solid arrows indicate experimental data and dashed arrows represent possible pathways based on the current literature (see text for details) 
As mentioned above, SARS-CoV is also neuroinvasive and neurotropic in humans [67, 68] and it could therefore be associated with the development of a neurological disease. Furthermore, the involvement of SARS-CoV in CNS infections was underscored by the findings that made use of transgenic mouse models expressing the human angiotensin-converting enzyme-2 (the cellular receptor used by SARS-CoV to infect susceptible cells). Indeed, using these mice, it was shown that SARS-CoV could invade the CNS after an intranasal infection primarily through the olfactory bulb [95] or even after an intraperitoneal infection [125], with concomitant neuronal loss [95, 125]; a phenomenon that can eventually lead to neurological problems.

\section{Conclusions and Significance}

The presence of coronaviruses in the human central nervous system is now a recognized fact as they appear to be part of a viral flora of the brain, with potential neuropathological consequences in genetically or otherwise susceptible individuals, with or without additional environmental insults. Knowledge of mechanisms and consequences of virus interactions with the nervous system is essential to better understand potentially pathological consequences and design intervention strategies that are appropriate to encephalitis or exacerbations of other types of neurological diseases for which a given virus is involved. In that regard, Hill's criteria adapted by Giovannoni and collaborators may represent a highly relevant tool to evaluate the relevance of human coronaviruses as a factor which will influence the development and/or exacerbation of a chronic human neurological disease potentially related to a viral infection. Therefore, collecting new data will be instrumental to our understanding of how the ubiquitous human coronaviruses, given the proper susceptibility conditions and proper virus evolution and infection conditions, could participate in the induction or exacerbation of human neuropathologies.

\section{References}

1. Vareille M, Kieninger E, Edwards MR, Regamey N (2011) The airway epithelium: soldier in the fight against respiratory viruses. Clin Microbiol Rev 24(1):210-229. doi:10.1128/ CMR.00014-10

2. Jartti T, Jartti L, Ruuskanen O, Soderlund-Venermo M (2012) New respiratory viral infections. Curr Opin Pulm Med 18(3):271-278. doi:10.1097/MCP.0b013e328351f8d4

3. Ison MG, Hayden FG (2002) Viral infections in immunocompromised patients: what's new with respiratory viruses? Curr Opin Infect Dis 15(4):355-367

4. Cesario TC (2012) Viruses associated with pneumonia in adults. Clin Infect Dis 55(1):107-113. doi:10.1093/cid/cis297 
5. Sloots TP, Whiley DM, Lambert SB, Nissen MD (2008) Emerging respiratory agents: new viruses for old diseases? J Clin Virol 42(3):233-243. doi:10.1016/j.jcv.2008.03.002

6. Brouard J, Vabret A, Nimal-Cuvillon D, Bach N, Bessiere A, Arion A, Freymuth F (2007) Epidemiology of acute upper and lower respiratory tract infections in children. Rev Prat 57(16):1759-1766

7. McGavern DB, Kang SS (2011) Illuminating viral infections in the nervous system. Nat Rev Immunol 11(5):318-329. doi:10.1038/nri2971

8. Giraudon P, Bernard A (2010) Inflammation in neuroviral diseases. J Neural Trans 117(8):899-906. doi:10.1007/s00702-010-0402-y

9. Whitley RJ, Gnann JW (2002) Viral encephalitis: familiar infections and emerging pathogens. Lancet 359(9305):507-513. doi:10.1016/S0140-6736(02)07681-X

10. Hankins DG, Rosekrans JA (2004) Overview, prevention, and treatment of rabies. Mayo Clin Proc 79(5):671-676

11. Aurelian L (2005) HSV-induced apoptosis in herpes encephalitis. Curr Top Microbiol Immunol 289:79-111

12. Mackenzie JS, Gubler DJ, Petersen LR (2004) Emerging flaviviruses: the spread and resurgence of Japanese encephalitis, West Nile and dengue viruses. Nat Med 10(12 suppl):S98-S109. doi:10.1038/nm1144

13. Mattson MP, Haughey NJ, Nath A (2005) Cell death in HIV dementia. Cell Death Differ 12(1):893-904. doi:10.1038/sj.cdd.4401577

14. Nath A, Berger J (2004) HIV Dementia. Curr Treat Opt Neurol 6(2):139-151

15. Gordon J, Gallia GL, Del Valle L, Amini S, Khalili K (2000) Human polyomavirus JCV and expression of myelin genes. J Neurovirol 6(suppl 2):S92-S97

16. Weissert R (2011) Progressive multifocal leukoencephalopathy. J Neuroimmunol 231(1-2):73-77. doi:10.1016/j.jneuroim.2010.09.021

17. Rima BK, Duprex WP (2005) Molecular mechanisms of measles virus persistence. Virus Res 111(2):132-147. doi:10.1016/j.virusres.2005.04.005

18. Kaplan JE, Osame M, Kubota H, Igata A, Nishitani H, Maeda Y, Khabbaz RF, Janssen RS (1990) The risk of development of HTLV-I-associated myelopathy/tropical spastic paraparesis among persons infected with HTLV-I. J Acquir Immune Defic Syndr 3(11):1096-1101

19. Itzhaki RF, Wozniak MA, Appelt DM, Balin BJ (2004) Infiltration of the brain by pathogens causes Alzheimer's disease. Neurobiol Aging 25(5):619-627. doi:10.1016/j.neurobiolaging. 2003.12.021

20. Stensballe LG, Devasundaram JK, Simoes EA (2003) Respiratory syncytial virus epidemics: the ups and downs of a seasonal virus. Pediatr Infect Dis J 22(2):S21-S32. doi:10.1097/01.inf.0000053882.70365.c9

21. Kawashima H, Ioi H, Ushio M, Yamanaka G, Matsumoto S, Nakayama T (2009) Cerebrospinal fluid analysis in children with seizures from respiratory syncytial virus infection. Scand J Infect Dis 41(3):228-231. doi:10.1080/00365540802669543

22. Zlateva KT, Van Ranst M (2004) Detection of subgroup B respiratory syncytial virus in the cerebrospinal fluid of a patient with respiratory syncytial virus pneumonia. Pediatr Infect Dis J 23(11):1065-1066

23. Morichi S, Kawashima H, Ioi H, Yamanaka G, Kashiwagi Y, Hoshika A, Nakayama T, Watanabe Y (2011) Classification of acute encephalopathy in respiratory syncytial virus infection. J Infect Chemother 17(6):776-781. doi:10.1007/s10156-011-0259-5

24. Millichap JJ, Wainwright MS (2009) Neurological complications of respiratory syncytial virus infection: case series and review of literature. J Child Neurol 24(12):1499-1503. doi: $10.1177 / 0883073808331362$

25. Espinoza JA, Bohmwald K, Cespedes PF, Gomez RS, Riquelme SA, Cortes CM, Valenzuela JA, Sandoval RA, Pancetti FC, Bueno SM, Riedel CA, Kalergis AM (2013) Impaired learning resulting from respiratory syncytial virus infection. Proc Natl Acad Sci USA 110(22):9112-9117. doi:10.1073/pnas.1217508110 
26. O’Donnell LA, Rall GF (2010) Blue moon neurovirology: the merits of studying rare CNS diseases of viral origin. J Neuroimmune Pharmacol 5(3):443-455. doi:10.1007/ s11481-010-9200-4

27. Wilson MR, Ludlow M, Duprex WP (2013) Human paramyxoviruses and infections of the central nervous system. In: Singh SK, Ruzek D (eds) Neuroviral infections. RNA viruses and retroviruses. CRC Press/Taylor and Francis, Boca Raton, pp 341-372

28. Escaffre O, Borisevich V, Rockx B (2013) Pathogenesis of Hendra and Nipah virus infection in humans. J Infect Dev Ctries 7(4):308-311. doi:10.3855/jidc.3648

29. Wong KT (2010) Emerging epidemic viral encephalitides with a special focus on henipaviruses. Acta Neuropathol 120(3):317-325. doi:10.1007/s00401-010-0720-z

30. Munster VJ, Prescott JB, Bushmaker T, Long D, Rosenke R, Thomas T, Scott D, Fischer ER, Feldmann H, de Wit E (2012) Rapid Nipah virus entry into the central nervous system of hamsters via the olfactory route. Sci Rep 2:736. doi:10.1038/srep00736

31. Zeng J, Wang G, Kang-Sheng L (2013) Influenza virus and CNS infections. In: Singh SK, Ruzek D (eds) Neuroviral Infections. RNA viruses and retroviruses. CRC Press/Taylor and Francis, Boca Raton, pp 325-339

32. Kuiken T, Riteau B, Fouchier RA, Rimmelzwaan GF (2012) Pathogenesis of influenza virus infections: the good, the bad and the ugly. Curr Opin Virol 2(3):276-286. doi:10.1016/j. coviro.2012.02.013

33. Matsuzaki Y, Katsushima N, Nagai Y, Shoji M, Itagaki T, Sakamoto M, Kitaoka S, Mizuta K, Nishimura H (2006) Clinical features of influenza C virus infection in children. J Infect Dis 193(9):1229-1235. doi:10.1086/502973

34. Gouarin S, Vabret A, Dina J, Petitjean J, Brouard J, Cuvillon-Nimal D, Freymuth F (2008) Study of influenza C virus infection in France. J Med Virol 80(8):1441-1446. doi:10.1002/ jmv. 21218

35. Munier S, Moisy D, Marc D, Naffakh N (2010) Interspecies transmission, adaptation to humans and pathogenicity of animal influenza viruses. Pathol Biol 58(2):e59-e68. doi:10. 1016/j.patbio.2010.01.012

36. Nicholson KG, Wood JM, Zambon M (2003) Influenza. Lancet 362(9397):1733-1745. doi:10.1016/S0140-6736(03)14854-4

37. Jang H, Boltz DA, Webster RG, Smeyne RJ (2009) Viral parkinsonism. Biochim Biophys Acta 1792(7):714-721. doi:10.1016/j.bbadis.2008.08.001

38. Wang GF, Li W, Li K (2010) Acute encephalopathy and encephalitis caused by influenza virus infection. Curr Opin Neurol 23(3):305-311

39. Millichap JG, Millichap JJ (2006) Role of viral infections in the etiology of febrile seizures. Pediatr Neurol 35(3):165-172. doi:10.1016/j.pediatrneurol.2006.06.004

40. Toovey S (2008) Influenza-associated central nervous system dysfunction: a literature review. Travel Med Infect Dis 6(3):114-124. doi:10.1016/j.tmaid.2008.03.003

41. Ozkale Y, Erol I, Ozkale M, Demir S, Alehan F (2012) Acute disseminated encephalomyelitis associated with influenza A H1N1 infection. Pediatr Neurol 47(1):62-64. doi:10.1016/j.pediatrneurol.2012.03.019

42. Beraki S, Aronsson F, Karlsson H, Ogren SO, Kristensson K (2005) Influenza A virus infection causes alterations in expression of synaptic regulatory genes combined with changes in cognitive and emotional behaviors in mice. Mol Psychiatry 10(3):299-308. doi:10.1038/sj.mp.4001545

43. Jurgens HA, Amancherla K, Johnson RW (2012) Influenza infection induces neuroinflammation, alters hippocampal neuron morphology, and impairs cognition in adult mice. J Neurosci 32(12):3958-3968. doi:10.1523/JNEUROSCI.6389-11.2012

44. Vabret A, Dina J, Brison E, Brouard J, Freymuth F (2009) Human coronaviruses. Pathol Biol 57(2):149-160. doi:10.1016/j.patbio.2008.02.018

45. Buchmeier MJ, Lane TE (1999) Viral-induced neurodegenerative disease. Curr Opin Microbiol 2 (4):398-402. doi:mc2416 [pii]

46. Cavanagh D (2005) Coronaviruses in poultry and other birds. Avian Pathol 34(6):439-448. doi:10.1080/03079450500367682 
47. Talbot PJ, Desforges, M, Brison, E, Jacomy, H (2011) Coronaviruses as Encephalitisinducing infectious agents. In: Tkachev S (ed) Non-flavirus Encephalitis. In-Tech, pp 185-202

48. Desforges M, Favreau DJ, Brison E, Desjardins J, Meessen-Pinard M, Jacomy H, Talbot PJ (2013) Human coronaviruses. Respiratory pathogens revisited as infectious neuroinvasive, neurotropic, and neurovirulent agents. In: Singh SK, Ruzek D (eds) Neuroviral infections. RNA viruses and retroviruses. CRC Press/Taylor and Francis, Boca Raton, pp 93-121

49. de Groot RJ, Baker SC, Baric R, Enjuanes L, Gorbalenya AE, Holmes KV, Perlman S, Poon L, Rottier PJM, Talbot PJ, Woo PCY, Ziebuhr J (eds) (2012) Family coronaviridae. Virus taxonomy: ninth report of the international commitee on taxonomy of viruses. Elsevier, New York

50. de Groot RJ, Baker SC, Baric RS, Brown CS, Drosten C, Enjuanes L, Fouchier RA, Galiano M, Gorbalenya AE, Memish Z, Perlman S, Poon LL, Snijder EJ, Stephens GM, Woo PC, Zaki AM, Zambon M, Ziebuhr J (2013) Middle East respiratory syndrome coronavirus (MERS-CoV); Announcement of the Coronavirus Study Group. J Virol. doi:10.1128/JVI. 01244-13

51. Saif LJ (2008) Coronaviruses of domestic livestock and poultry: interspecies transmission, pathogenesis, and immunity. In: Perlman S, Gallagher T, Snijder EJ (eds) Nidoviruses. ASM Press, Washington D.C, pp 279-298

52. Foley JE, Lapointe JM, Koblik P, Poland A, Pedersen NC (1998) Diagnostic features of clinical neurologic feline infectious peritonitis. J Vet Intern Med 12(6):415-423

53. Kline K, Joseph R, Averill DAJ (1994) Feline infectious peritonitis with neurological involvement: clinical and pathological findings in 24 cats. J Am Anim Hosp Assoc 30:111-118

54. Foley JE, Rand C, Leutenegger C (2003) Inflammation and changes in cytokine levels in neurological feline infectious peritonitis. J Feline Med Surg 5(6):313-322

55. Slauson DO, Finn JP (1972) Meningoencephalitis and panophthalmitis in feline infectious peritonitis. J Am Vet Med Assoc 160(5):729-734

56. Legendre AM, Whitenack DL (1975) Feline infectious peritonitis with spinal cord involvement in two cats. J Am Vet Med Assoc 167(10):31-32

57. Greig AS, Mitchell D, Corner AH, Bannister GL, Meads EB, Julian RJ (1962) A hemagglutinating virus producing encephalomyelitis in baby pigs. Can J Comp Med Vet Sci 26(3):49-56

58. Alexander TJ (1962) Viral encephalomyelitis of swine in Ontario-experimental and natural transmission. Am J Vet Res 23:756-762

59. Andries K, Pensaert MB (1980) Virus isolated and immunofluorescence in different organs of pigs infected with hemagglutinating encephalomyelitis virus. Am $\mathrm{J}$ Vet Res 41(2):215-218

60. Hirano N, Nomura R, Tawara T, Tohyama K (2004) Neurotropism of swine haemagglutinating encephalomyelitis virus (coronavirus) in mice depending upon host age and route of infection. J Comp Pathol 130(1):58-65

61. Weiss SR, Leibowitz JL (2011) Coronavirus pathogenesis. Advances in virus research, vol 81. Elsevier, Boston, pp 85-164

62. Brian DA, Baric RS (2005) Coronavirus genome structure and replication. Curr Top Microbiol Immunol 287:1-30

63. Arbour N, Day R, Newcombe J, Talbot PJ (2000) Neuroinvasion by human respiratory coronaviruses. J Virol 74(19):8913-8921

64. Arbour N, Cote G, Lachance C, Tardieu M, Cashman NR, Talbot PJ (1999) Acute and persistent infection of human neural cell lines by human coronavirus OC43. J Virol 73(4):3338-3350

65. Arbour N, Ekande S, Cote G, Lachance C, Chagnon F, Tardieu M, Cashman NR, Talbot PJ (1999) Persistent infection of human oligodendrocytic and neuroglial cell lines by human coronavirus 229E. J Virol 73(4):3326-3337 
66. Bonavia A, Arbour N, Yong VW, Talbot PJ (1997) Infection of primary cultures of human neural cells by human coronaviruses 229E and OC43. J Virol 71(1):800-806

67. Xu J, Zhong S, Liu J, Li L, Li Y, Wu X, Li Z, Deng P, Zhang J, Zhong N, Ding Y, Jiang Y (2005) Detection of severe acute respiratory syndrome coronavirus in the brain: potential role of the chemokine mig in pathogenesis. Clin Infect Dis 41(8):1089-1096. doi:10.1086/ 444461

68. Gu J, Gong E, Zhang B, Zheng J, Gao Z, Zhong Y, Zou W, Zhan J, Wang S, Xie Z, Zhuang H, Wu B, Zhong H, Shao H, Fang W, Gao D, Pei F, Li X, He Z, Xu D, Shi X, Anderson VM, Leong AS (2005) Multiple organ infection and the pathogenesis of SARS. J Exp Med 202(3):415-424. doi:10.1084/jem.20050828

69. Talbot PJ, Jacomy H, Desforges M (2008) Pathogenesis of human coronaviruses other than severe acute respiratory syndrome coronavirus. In: Perlman S, Gallagher T, Snijder EJ (eds) Nidoviruses. ASM Press, Washington D.C, pp 313-324

70. http://www.who.int/csr/don/2013_08_30/en/index.html

71. Jacomy H, Fragoso G, Almazan G, Mushynski WE, Talbot PJ (2006) Human coronavirus OC43 infection induces chronic encephalitis leading to disabilities in BALB/C mice. Virology 349(2):335-346. doi:10.1016/j.virol.2006.01.049

72. Myint SH (1995) Human coronavirus infections. In: Siddell SG (ed) The coronaviridae. Plenum Press, New York, pp 389-401

73. Drosten C, Gunther S, Preiser W, van der Werf S, Brodt HR, Becker S, Rabenau H, Panning M, Kolesnikova L, Fouchier RA, Berger A, Burguiere AM, Cinatl J, Eickmann M, Escriou N, Grywna K, Kramme S, Manuguerra JC, Muller S, Rickerts V, Sturmer M, Vieth S, Klenk HD, Osterhaus AD, Schmitz H, Doerr HW (2003) Identification of a novel coronavirus in patients with severe acute respiratory syndrome. N Eng J Med 348(20):1967-1976. doi:10. 1056/NEJMoa030747

74. Fouchier RA, Kuiken T, Schutten M, van Amerongen G, van Doornum GJ, van den Hoogen BG, Peiris M, Lim W, Stohr K, Osterhaus AD (2003) Aetiology: Koch's postulates fulfilled for SARS virus. Nature 423(6937):240. doi:10.1038/423240a

75. van der Hoek L, Pyrc K, Jebbink MF, Vermeulen-Oost W, Berkhout RJ, Wolthers KC, Wertheim-van Dillen PM, Kaandorp J, Spaargaren J, Berkhout B (2004) Identification of a new human coronavirus. Nat Med 10(4):368-373. doi:10.1038/nm1024

76. Woo PC, Lau SK, Chu CM, Chan KH, Tsoi HW, Huang Y, Wong BH, Poon RW, Cai JJ, Luk WK, Poon LL, Wong SS, Guan Y, Peiris JS, Yuen KY (2005) Characterization and complete genome sequence of a novel coronavirus, coronavirus HKU1, from patients with pneumonia. J Virol 79(2):884-895. doi:10.1128/JVI.79.2.884-895.2005

77. Zaki AM, van Boheemen S, Bestebroer TM, Osterhaus AD, Fouchier RA (2012) Isolation of a novel coronavirus from a man with pneumonia in Saudi Arabia. N Engl J Med 367(19):1814-1820. doi:10.1056/NEJMoa1211721

78. Severance EG, Dickerson FB, Viscidi RP, Bossis I, Stallings CR, Origoni AE, Sullens A, Yolken RH (2011) Coronavirus immunoreactivity in individuals with a recent onset of psychotic symptoms. Schizophr Bull 37(1):101-107. doi:10.1093/schbul/sbp052

79. Fuk-Woo Chan J, Chan KH, Choi GK, To KK, Tse H, Cai JP, Yeung ML, Cheng VC, Chen H, Che XY, Lau SK, Woo PC, Yuen KY (2013) Differential cell line susceptibility to the emerging novel human betacoronavirus 2c EMC/2012: implications for disease pathogenesis and clinical manifestation. J Infect Dis 207(11):1743-1752. doi:10.1093/ infdis/jit123

80. Berth SH, Leopold PL, Morfini GN (2009) Virus-induced neuronal dysfunction and degeneration. Front Biosci 14:5239-5259

81. Kim WK, Corey S, Alvarez X, Williams K (2003) Monocyte/macrophage traffic in HIV and SIV encephalitis. J Leukoc Biol 74(5):650-656. doi:10.1189/jlb.0503207

82. Argyris EG, Acheampong E, Wang F, Huang J, Chen K, Mukhtar M, Zhang H (2007) The interferon-induced expression of APOBEC3G in human blood-brain barrier exerts a potent intrinsic immunity to block HIV-1 entry to central nervous system. Virology 367(2):440-451. doi:10.1016/j.virol.2007.06.010 
83. Desforges M, Miletti TC, Gagnon M, Talbot PJ (2007) Activation of human monocytes after infection by human coronavirus 229E. Virus Res 130(1-2):228-240. doi:10.1016/j. virusres.2007.06.016

84. Collins AR (2002) In vitro detection of apoptosis in monocytes/macrophages infected with human coronavirus. Clin Diagn Lab Immunol 9(6):1392-1395

85. Wentworth DE, Tresnan DB, Turner BC, Lerman IR, Bullis B, Hemmila EM, Levis R, Shapiro LH, Holmes KV (2005) Cells of human aminopeptidase N (CD13) transgenic mice are infected by human coronavirus-229E in vitro, but not in vivo. Virology 335(2):185-197. doi:10.1016/j.virol.2005.02.023

86. Nicholls JM, Butany J, Poon LL, Chan KH, Beh SL, Poutanen S, Peiris JS, Wong M (2006) Time course and cellular localization of SARS-CoV nucleoprotein and RNA in lungs from fatal cases of SARS. PLoS Med 3(2):e27. doi:10.1371/journal.pmed.0030027

87. Spiegel M, Schneider K, Weber F, Weidmann M, Hufert FT (2006) Interaction of severe acute respiratory syndrome-associated coronavirus with dendritic cells. J Gen Virol 87(Pt 7):1953-1960. doi:10.1099/vir.0.81624-0

88. Reuter JD, Gomez DL, Wilson JH, Van Den Pol AN (2004) Systemic immune deficiency necessary for cytomegalovirus invasion of the mature brain. J Virol 78(3):1473-1487

89. Lassnig C, Sanchez CM, Egerbacher M, Walter I, Majer S, Kolbe T, Pallares P, Enjuanes L, Muller M (2005) Development of a transgenic mouse model susceptible to human coronavirus 229E. Proc Nat Acad Sci U S A 102(23):8275-8280. doi:10.1073/pnas. 0408589102

90. Guo Y, Korteweg C, McNutt MA, Gu J (2008) Pathogenetic mechanisms of severe acute respiratory syndrome. Virus Res 133(1):4-12. doi:10.1016/j.virusres.2007.01.022

91. Jacomy H, Talbot PJ (2003) Vacuolating encephalitis in mice infected by human coronavirus OC43. Virology 315(1):20-33

92. McCray PB Jr, Pewe L, Wohlford-Lenane C, Hickey M, Manzel L, Shi L, Netland J, Jia HP, Halabi C, Sigmund CD, Meyerholz DK, Kirby P, Look DC, Perlman S (2007) Lethal infection of K18-hACE2 mice infected with severe acute respiratory syndrome coronavirus. J Virol 81(2):813-821. doi:10.1128/JVI.02012-06

93. Butler N, Pewe L, Trandem K, Perlman S (2006) Murine encephalitis caused by HCoVOC43, a human coronavirus with broad species specificity, is partly immune-mediated. Virology 347(2):410-421. doi:10.1016/j.virol.2005.11.044

94. St-Jean JR, Jacomy H, Desforges M, Vabret A, Freymuth F, Talbot PJ (2004) Human respiratory coronavirus OC43: genetic stability and neuroinvasion. $\mathrm{J}$ Virol 78(16):8824-8834. doi:10.1128/JVI.78.16.8824-8834.2004

95. Netland J, Meyerholz DK, Moore S, Cassell M, Perlman S (2008) Severe acute respiratory syndrome coronavirus infection causes neuronal death in the absence of encephalitis in mice transgenic for human ACE2. J Virol 82(15):7264-7275. doi:10.1128/JVI.00737-08

96. Koch R (1942) The aetiology of tuberculosis (translation of Die Aetiologie der Tuberculose (1882). Dover Publications, New York

97. Fredericks DN, Relman DA (1996) Sequence-based identification of microbial pathogens: a reconsideration of Koch's postulates. Clin Microbiol Rev 9(1):18-33

98. Hill AB (1965) The environment and disease: association or causation? Proc R Soc Med 58:295-300

99. Giovannoni G, Cutter GR, Lunemann J, Martin R, Munz C, Sriram S, Steiner I, Hammerschlag MR, Gaydos CA (2006) Infectious causes of multiple sclerosis. Lancet Neurol 5(10):887-894. doi:10.1016/S1474-4422(06)70577-4

100. Yeh EA, Collins A, Cohen ME, Duffner PK, Faden H (2004) Detection of coronavirus in the central nervous system of a child with acute disseminated encephalomyelitis. Pediatrics 113(1 Pt 1):e73-e76

101. Kurtzke JF (1993) Epidemiologic evidence for multiple sclerosis as an infection. Clin Microbiol Rev 6(4):382-427

102. Cusick MF, Libbey JE, Fujinami RS (2013) Multiple sclerosis: autoimmunity and viruses. Curr Opin Rheumatol 25(4):496-501. doi:10.1097/BOR.0b013e328362004d 
103. Kakalacheva K, Munz C (1812) Lunemann JD (2011) Viral triggers of multiple sclerosis. Biochim Biophys Acta 2:132-140. doi:10.1016/j.bbadis.2010.06.012

104. Gilden DH (2005) Infectious causes of multiple sclerosis. Lancet Neurol 4(3):195-202. doi:10.1016/S1474-4422(05)01017-3

105. Talbot PJ, Arnold D, Antel JP (2001) Virus-induced autoimmune reactions in the CNS. Curr Top Microbiol Immunol 253:247-271

106. Hovanec DL, Flanagan TD (1983) Detection of antibodies to human coronaviruses 229E and OC43 in the sera of multiple sclerosis patients and normal subjects. Infect Immun 41(1):426-429

107. Sibley WA, Bamford CR, Clark K (1985) Clinical viral infections and multiple sclerosis. Lancet 1(8441):1313-1315

108. Boucher A, Desforges M, Duquette P, Talbot PJ (2007) Long-term human coronavirusmyelin cross-reactive T-cell clones derived from multiple sclerosis patients. Clin Immunol 123(3):258-267. doi:10.1016/j.clim.2007.02.002

109. Talbot PJ, Paquette JS, Ciurli C, Antel JP, Ouellet F (1996) Myelin basic protein and human coronavirus 229E cross-reactive T-cells in multiple sclerosis. Ann Neurol 39(2):233-240. doi:10.1002/ana.410390213

110. Matthews AE, Weiss SR, Paterson Y (2002) Murine hepatitis virus-a model for virusinduced CNS demyelination. J Neurovirol 8(2):76-85. doi:10.1080/13550280290049534

111. Jacomy H, St-Jean JR, Brison E, Marceau G, Desforges M, Talbot PJ (2010) Mutations in the spike glycoprotein of human coronavirus OC43 modulate disease in BALB/c mice from encephalitis to flaccid paralysis and demyelination. J Neurovirol 16(4):279-293. doi:10. 3109/13550284.2010.497806

112. St-Jean JR, Desforges M, Talbot PJ (2006) Genetic evolution of human coronavirus OC43 in neural cell culture. Adv Exp Med Biol 581:499-502. doi:10.1007/978-0-387-33012-9_88

113. Brison E, Jacomy H, Desforges M, Talbot PJ (2011) Glutamate excitotoxicity is involved in the induction of paralysis in mice after infection by a human coronavirus with a single point mutation in its spike protein. J Virol 85(23):12464-12473. doi:10.1128/JVI.05576-11

114. Amor S, Puentes F, Baker D, van der Valk P (2010) Inflammation in neurodegenerative diseases. Immunology 129(2):154-169. doi:10.1111/j.1365-2567.2009.03225.x

115. Carmen J, Rothstein JD, Kerr DA (2009) Tumor necrosis factor-alpha modulates glutamate transport in the CNS and is a critical determinant of outcome from viral encephalomyelitis. Brain Res 1263:143-154. doi:10.1016/j.brainres.2009.01.040

116. Favreau DJ, Desforges M, St-Jean JR, Talbot PJ (2009) A human coronavirus OC43 variant harboring persistence-associated mutations in the $\mathrm{S}$ glycoprotein differentially induces the unfolded protein response in human neurons as compared to wild-type virus. Virology 395(2):255-267. doi:10.1016/j.virol.2009.09.026

117. Favreau DJ, Desforges M, Talbot PJ (2011) Human coronavirus-induced neuronal programmed cell death is cyclophilin D-dependent and potentially caspase-dispensable. J Virol 86(1):81-93. doi:10.1128/JVI.06062-11

118. Galluzzi L, Vitale I, Abrams JM, Alnemri ES, Baehrecke EH, Blagosklonny MV, Dawson TM, Dawson VL, El-Deiry WS, Fulda S, Gottlieb E, Green DR, Hengartner MO, Kepp O, Knight RA, Kumar S, Lipton SA, Lu X, Madeo F, Malorni W, Mehlen P, Nunez G, Peter ME, Piacentini M, Rubinsztein DC, Shi Y, Simon HU, Vandenabeele P, White E, Yuan J, Zhivotovsky B, Melino G, Kroemer G (2012) Molecular definitions of cell death subroutines: recommendations of the nomenclature committee on cell death. Cell Death Differ 19(1):107-120. doi:10.1038/cdd.2011.96

119. Kaiser WJ, Upton JW, Mocarski ES (2013) Viral modulation of programmed necrosis. Curr Opin Virol. doi:10.1016/j.coviro.2013.05.019

120. Cali T, Ottolini D, Brini M (2011) Mitochondria, calcium, and endoplasmic reticulum stress in Parkinson's disease. BioFactors 37(3):228-240. doi:10.1002/biof.159

121. Bender SJ, Weiss SR (2010) Pathogenesis of murine coronavirus in the central nervous system. J Neuroimmune Pharmacol 5(3):336-354. doi:10.1007/s11481-010-9202-2 
122. Hosking MP, Lane TE (2010) The pathogenesis of murine coronavirus infection of the central nervous system. Crit Rev Immunol 30(2):119-130

123. Desforges M, Desjardins J, Zhang C, Talbot PJ (2013) The acetyl-esterase activity of the hemagglutinin-esterase protein of human coronavirus OC43 strongly enhances the production of infectious virus. J Virol 87(6):3097-3107. doi:10.1128/JVI.02699-1

124. Kazi L, Lissenberg A, Watson R, de Groot RJ, Weiss SR (2005) Expression of hemagglutinin esterase protein from recombinant mouse hepatitis virus enhances neurovirulence. J Virol 79(24):15064-15073. doi:10.1128/JVI.79.24.15064-15073.2005

125. Tseng CT, Huang C, Newman P, Wang N, Narayanan K, Watts DM, Makino S, Packard MM, Zaki SR, Chan TS, Peters CJ (2007) Severe acute respiratory syndrome coronavirus infection of mice transgenic for the human Angiotensin-converting enzyme 2 virus receptor. J Virol 81(3):1162-1173. doi:10.1128/JVI.01702-06 